\title{
Identification of a novel six autophagy- related genes signature for the prognostic and a miRNA-related autophagy predictor for anti-PD-1 therapy responses in prostate cancer
}

\author{
Lei $\mathrm{Wu}^{1+}$, Wen Quan ${ }^{1 \dagger}$, Guojun Yue ${ }^{2}$, Qiong Luo ${ }^{3}$, Dongxu Peng ${ }^{1}$, Ying Pan ${ }^{1 *}$ and Guihai Zhang ${ }^{1,2^{*}}$
}

\begin{abstract}
Background: Autophagy is a highly conserved homeostatic process in the human body that is responsible for the elimination of aggregated proteins and damaged organelles. Several autophagy-related genes (ARGs) contribute to the process of tumorigenesis and metastasis of prostate cancer (PCa). Also, miRNAs have been proven to modulate autophagy by targeting some ARGs. However, their potential role in PCa still remains unclear.
\end{abstract}

Methods: An univariate Cox proportional regression model was used to identify 17 ARGs associated with the overall survival (OS) of PCa. Then, a multivariate Cox proportional regression model was used to construct a 6 autophagy-related prognostic genes signature. Patients were divided into low-risk group and high-risk group using the median risk score as a cutoff value. High-risk patients had shorter OS than low-risk patients. Furthermore, the signature was validated by ROC curves. Regarding mRNA and miRNA, 12 differentially expressed miRNAs (DEMs) and 1073 differentially expressed genes (DEGs) were detected via the GEO database. We found that miR-205, one of the DEMs, was negatively regulated the expression of ARG (NKX2-3). Based on STRING analysis results, we found that the NKX2-3 was moderately related to the part of genes among the 6 autophagy-related genes prognostic signature. Further, NKX 2-3 was significantly correlated with OS and some clinical parameters of PCa by cBioProtal. By gene set enrichment analysis (GSEA). Lastly, we demonstrated that the association between NKX2-3 and tumor mutation burden (TMB) and PDCD1 (programmed cell death 1) of PCa.

Results: We identified that the six ARGs expression patterns are independent predictors of OS in PCa patients. Furthermore, our results suggest that ARGs and miRNAs are inter-related. MiR-205 was negatively regulated the expression of ARG (NKX2-3). Further analysis demonstrated that NKX2-3 may be a potential biomarker for predicting the efficacy of anti-PD-1 therapy in PCa.

(Continued on next page)

\footnotetext{
*Correspondence: pyzhhospital@163.com; zghzhsymyy@163.com

${ }^{+}$Lei Wu and Wen Quan contributed equally to this work.

'Department of Oncology, Zhuhai People's Hospital (Zhuhai Hospital affiliated with Jinan University), Zhuhai, Guangdong Province, P. R. China Full list of author information is available at the end of the article
}

(c) The Author(s). 2021 Open Access This article is licensed under a Creative Commons Attribution 4.0 International License, which permits use, sharing, adaptation, distribution and reproduction in any medium or format, as long as you give appropriate credit to the original author(s) and the source, provide a link to the Creative Commons licence, and indicate if changes were made. The images or other third party material in this article are included in the article's Creative Commons. licence, unless indicated otherwise in a credit line to the material. If material is not included in the article's Creative Commons licence and your intended use is not permitted by statutory regulation or exceeds the permitted use, you will need to obtain permission directly from the copyright holder. To view a copy of this licence, visit http://creativecommons.org/licenses/by/4.0/ The Creative Commons Public Domain Dedication waiver (http://creativecommons.org/publicdomain/zero/1.0/) applies to the data made available in this article, unless otherwise stated in a credit line to the data. 
(Continued from previous page)

Conclusions: The current study may offer a novel autophagy-related prognostic signature and may identify a promising miRNA-ARG pathway for predicting the efficacy of anti-PD-1 therapy in PCa.

Keywords: Autophagy, miRNA, Prostate cancer, PD-1

\section{Background}

Prostate cancer is one of the most common malignancies in men. The incidence of prostate cancer has been increasing worldwide in recent years [1]. Many patients within the early stage have a good prognosis after several effective therapies. Nevertheless, some progressive prostate cancer patients with advanced-stage are more resistant to the conventional treatments. As a result, these patients have a poor prognosis and high cancer-related mortality [2]. Therefore, it is imperative to develop some novel and effective therapeutic strategies for prostate cancer patients.

Autophagy is a major physiological process responsible for the elimination of aggregated proteins and damaged organelles [3]. Increasing studies have shown that autophagy is closely associated with various cancers, including prostate cancer [4-6]. Nevertheless, the mechanism of autophagy in tumorigenesis is multifaceted [7]. Previous experiments have demonstrated that autophagy has been considered as a double-edged sword in carcinogenesis, which either promotes or inhibits the development of cancers in different stages [8]. Before a tumor develops, autophagy is thought to prevent cancer development in non-cancerous cells by eradicating damaged organelles and oncogenic protein substrates $[9,10]$. However, once the cancer has developed, autophagy protects tumor cells against stress as an adaptive response, and thus promotes tumor progression $[11,12]$. It is obvious that autophagy is a promising therapeutic target for cancer therapy. Thus, it is essential to discover the autophagy-related mechanism in cancer and its therapeutic targeting in tumor microenvironment.

MicroRNAs (miRNAs) are a family of endogenous non-coding RNAs that negatively control gene expression at the post-transcriptional level [13, 14]. Aberrant expression of miRNA is essential for the occurrence and development of human malignant tumors, because they act as both tumor suppressors and oncogenes [15]. Numerous studies have demonstrated that some miRNAs significantly modulate the biological behaviors of prostate cancer [16]. For instance, miR-29b inhibits prostate tumor growth by targeting Bim [17]. MiR-135a regulates apoptosis in prostate cancer through the inhibition of STAT6 [18]. Downregulated expression of miR-139-5p promotes prostate cancer progression by targeting SOX5 [19]. Further, miRNAs also can be invoked as potential prognostic biomarkers in prostate cancer [20-22].
Numerous studies have confirmed that many miRNAs can affect the biological behaviors of multiple tumor tissues by regulating autophagy-related genes or pathways [23-26]. However, the role of miRNAs and autophagy in tumorigenesis have analyzed a limited number of ARGs and miRNAs in prostate cancer in most of the previous studies. Hence, the prognostic value of ARGs and the regulatory mechanism of ARGs and miRNAs have not been clearly and completely realized in prostate cancer. Therefore, it will be useful to further understand the regulation mechanisms between autophagy and miRNAs in prostate cancer.

In our study, we presented NKX2-3 as one of the prognostic biomarkers for $\mathrm{PCa}$ and founded that NKX2-3 relied to the autophagy is highly expressed in PCa tissues. Meanwhile, NKX2-3 was significantly related to the clinical parameters and OS of prostate cancer patients. Additionally, miR-205 has decreased expression in PCa samples, compared with normal prostate samples. Herein, we characterize that NKX2-3 is up-regulated by miR-205. MiR-205/NKX2-3 regulation pathway may have a modulatory effect on autophagy in PCa. Finally, since the expression of NKX2-3 was specifically correlated with PD-1 and TMB, NKX2-3 may be used as a biomarker for the prediction of PD-1 efficacy in PCa.

\section{Methods}

\section{Acquisition of prostate cancer datasets}

The transcriptome expression profiles and corresponding clinical information of prostate cancer were obtained from the TCGA database. The expression data was HTSeq-FPKM type, containing 499 prostate cancer tissues and 52 adjacent non-tumor samples. GSE36802 and GSE69223 datasets were obtained from the Gene Expression Omnibus (GEO). Microarray data of GSE36802 and GSE69223 were on account of GPL8786 and GPL570 platforms, respectively. The GSE36802 dataset contained 42 samples including 21 prostate cancer tissues and 21 non-tumorous tissues. The GSE69223 dataset contained 30 samples including 15 prostate cancer tissues and 15 non-tumorous tissues. DEMs and DEGs were identified by comparing prostate cancer tissues with noncancerous prostate tissues using the limma package of $\mathrm{R}$ software (Version 3.6.1). $|\log \mathrm{FC}|>1$ and adjust $P$ value $<0.05$ were set as the cut-off values. 


\section{Human autophagy related genes}

The 232 autophagy-related genes were obtained from the Human Autophagy Database (HADb, http://autophagy.lu/clustering/index.html). These genes had been described involved in the autophagy process based on literature [27].

\section{Gene ontology and pathway enrichment analysis of the DEMs and DEGs}

Gene ontology (GO) and pathway analysis were performed using the functional enrichment analysis tool (FunRich v3.1.3), which included cellular component (CC), molecular function (MF), and biological process (BP), and a biological pathways pathway analysis of the DEMs and DEGs [28, 29]. $P<0.05$ was set as the cutoff criterion.

\section{Gene set enrichment analysis (GSEA)}

GSEA was carried out to analyze the biological pathway in prostate cancer stratified by the median expression of NKX2-3. The detailed process follows the recommended protocol from the Broad Institute Gene Set Enrichment Analysis website [30]. The GSEA was performed using the GSEA v4.0.3 software. The gene sets were adopted from The Molecular Signatures Database within the Hallmark gene sets [31]. NOM $p$-value $<0.05$ and FDR q-value $<0.05$ were recognized as statistically significant.

\section{Statistical analysis}

All statistics were performed with the $\mathrm{R}$ software (Version 3.6.1). $\times 2$ test and $t$-test were used to check for categorical variables and continuous variables, respectively. Based on the median value of risk score, Kaplan-Meier curves were plotted and a log-rank test was used to check the significant difference in overall survival between high-risk and low-risk groups. The receiver operating characteristic (ROC) analysis was used to examine the sensitivity and specificity of survival prediction using the gene signature risk score. An area under the ROC curve (AUC) served as an indicator of prognostic accuracy. Pearson correlations were used to examine correlations between variables. $P<0.05$ was considered statistically significant for all the analyses.

\section{Results}

Identification of an autophagy-related risk signature for the prognosis of prostate cancer

The prognostic value of ARGs was performed by univariate COX regression in 499 prostate tumor samples in the TCGA database. Seventeen genes (ATG16L1, FADD, GABARAPL2, NKX2-3, MYC, MAPK8IP1, WDR45B, MTMR14, HGS, USP10, NPC1, BIRC5, BNIP3, ATG3, RAB24, ULK3 and RUBCN) were identified to be significantly correlated with OS in prostate tumor samples. Among the 17 genes, all the genes were identified as risk factors $(p<0.05, \mathrm{HR}>1$, Fig. 1a). And then a multivariate Cox regression was performed to develop the following autophagy-related risk signature related to the survival of $\mathrm{PCa}$ patients. The calculation formula of risk score is as follows [32]: Risk score $=($ FADD expression $\times 2.341572)+($ GABARAPL2 expression $\times 4.34965)+$ $($ MYC expression $\times 2.430837)+($ RAB24 expression $\times$ $3.570068)+($ RUBCN expression $\times 4.857469)+(\mathrm{NPC} 1$ expression $\times 1.739033)$. Then patients were divided into low-risk group $(n=177)$ and high-risk group $(n=176)$ using the median risk score as a cutoff value. Our data showed that the survival time of high risk group is significantly shorter than the low risk group (Fig. 1b). Risk genes showed significant expression patterns according to the risk value (Fig. 1c) and all of the deaths occurred in the high-risk group (Fig. 1d). The heatmap of the 6 ARGs expression levels in the TCGA dataset, high-risk group expressed higher levels of risky genes (Fig. 1e). ROC curves for 3-year overall survival were performed to evaluate the predictive power of the six-gene risk signature (Fig. 1f). The 3-year AUC of our signature was 0.928 , which was obviously higher than that of age $(\mathrm{AUC}=0.580)$, tumor $\mathrm{T}$ stage $(\mathrm{AUC}=0.641)$, and tumor $\mathrm{N}$ stage $(\mathrm{AUC}=0.694)$.

\section{The correlation between the autophagy-related risk signature and clinical factors in prostate cancer}

An analysis was applied to compare the correlation between predicted 6-gene signature and conventional clinical factors of prostate cancer, Results showed that MYC expression was correlated with patients' age $(P=0.009)$. FADD expression was correlated with both $\mathrm{T}$ classification $(\mathrm{P}=0.009)$ and lymphatic invasion $(P=0.012)$. NPC1 expression was associated with lymphatic invasion $(P=0.017)$. RUBCN expression was correlated with lymphatic invasion $(P=2.098 \mathrm{e}-04)$. We further analyzed the correlation between the risk score and these clinical factors, we found that $\mathrm{T}$ classification was correlated with the risk score $(P=0.024)$ (Fig. 2$)$.

\section{Identification of DEMs and DEGs in prostate cancer}

There are 21 pairs of PCa samples and matched adjacent non-tumor prostate samples were collected and processed for microRNA detection, and mRNA expression analysis was performed by using 30 matched malignant and normal prostate tissue samples from 15 prostate cancer patients. All the samples were obtained from GEO. Results showed that a total of 12 DEMs and 1073 DEGs were detected. Considered as the criteria of $|\log \mathrm{FC}|>1$ and adjust $P$ value $<0.05$, we finally identified 2 up-regulated and 10 down-regulated DEMs (Fig.3a and c). Meanwhile, 413 


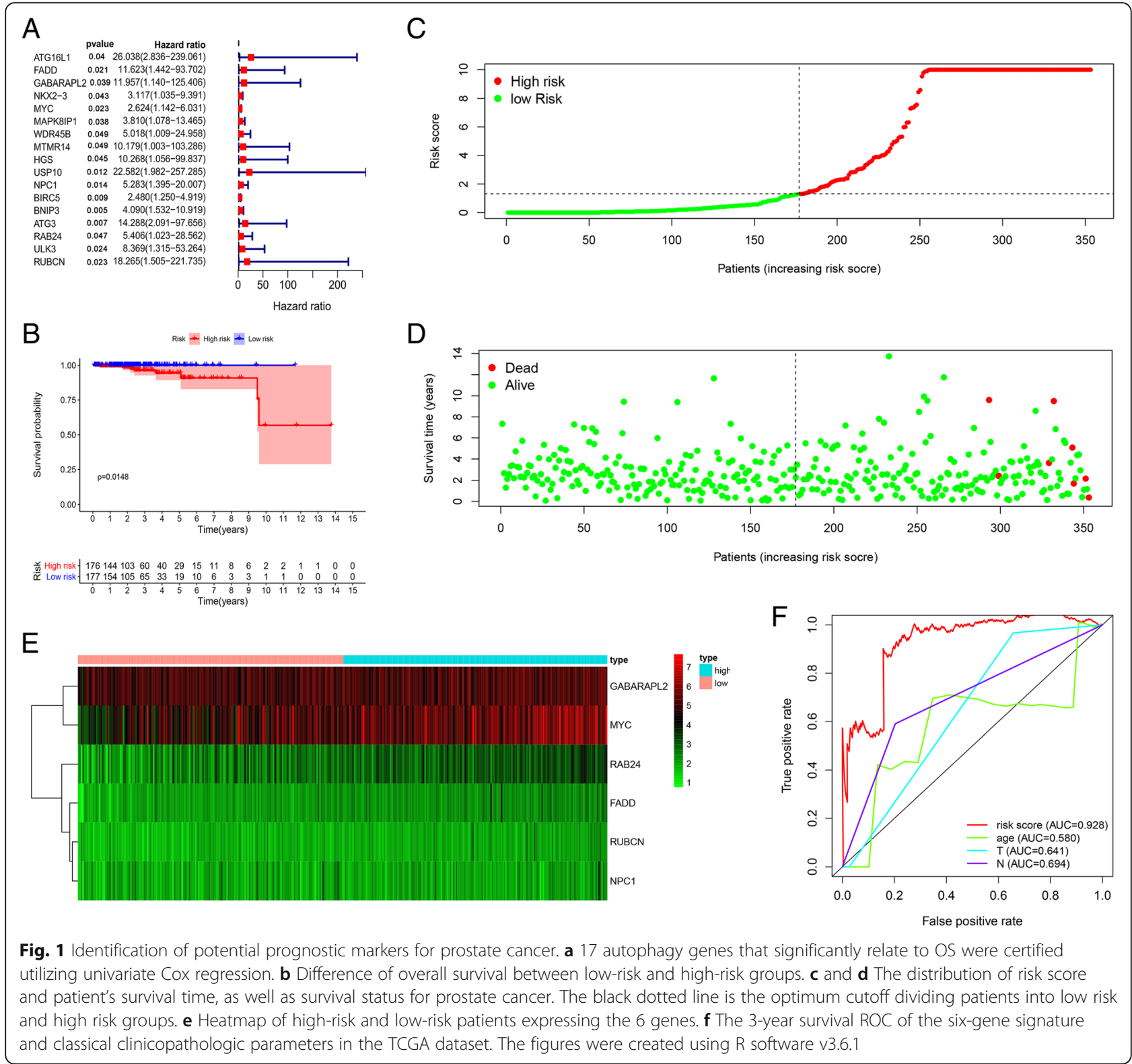

up-regulated and 660 down-regulated DEGs were extracted (Fig. $3 b$ and d).

\section{Enrichment analysis of the DEMs and DEGs}

To improve our understanding of the biological information of the 12 DEMs in prostate cancer, we performed GO annotation and biological pathway analyses by using the software of FunRich. Regarding BP, the DEmiRNAs were significantly enriched in regulation of nucleic acid metabolism, nucleotide, nucleoside, and nucleobase (Fig. 4a). Regarding CC, the DEmiRNAs were significantly enriched in nucleus, cytoplasm, lysosome, golgi apparatus, and endocytic vesicle membrane (Fig. 4b). In addition, the significantly enriched GO terms in MF was transcription factor activity (Fig. 4c). As shown in Fig. 4d, the pathways of biological processes were TRAIL signaling pathway, Class I PI3K signaling events mediated by Akt, PDGFR-beta pathway, mTOR signaling pathway, EGF receptor pathway, VEGF and VEGFR network, IFN-gamma pathway, ErbB receptor signaling network, Glypican pathway, and PDGF receptor signaling network. Alike, all 1073 DEGs were also uploaded to the FunRich, the results of GO analysis indicated that 1) for $\mathrm{BP}, \mathrm{DEGs}$ were significantly enriched in cell communication, signal transduction, and cell growth and/or maintenance; 2) for CC, DEGs were particularly enriched in the basement membrane, extracellular region, proteinaceous extracellular matrix, plasma membrane, extracellular 

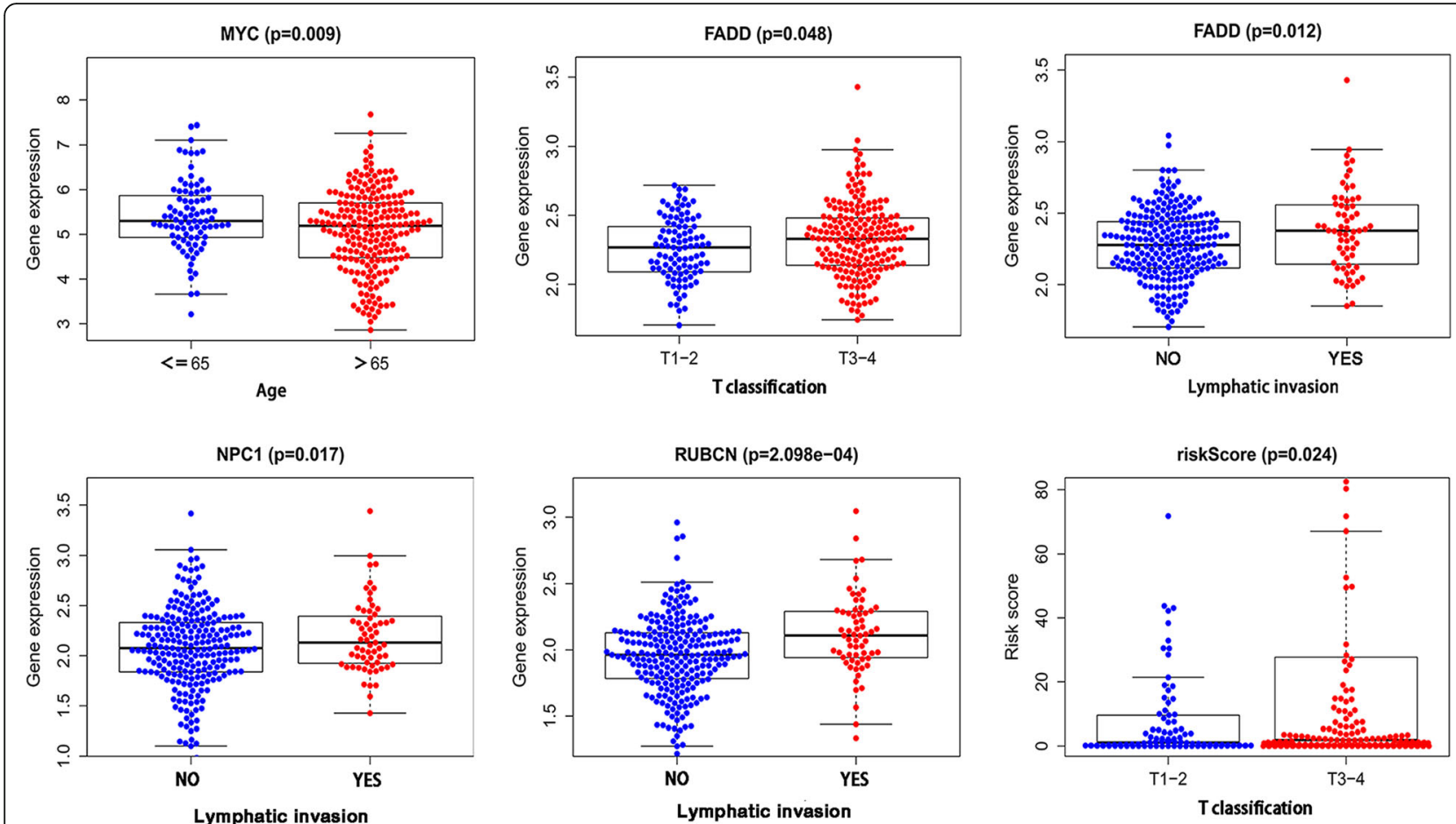

Fig. 2 The significance analysis of predicted gene signature association with clinical factors and the association between risk score and clinical factors. The figures were created using R software v3.6.1

space, extracellular matrix, and extracellular. 3) for MF, DEGs was only enriched in extracellular matrix structural constituent (Fig. 4e-g). Additionally, biological pathway analysis showed these DEGs were mostly enriched in mesenchymal-to-epithelial transition and epithelial-tomesenchymal transition (Fig. 4h).

\section{miRNA-mRNA network}

FunRich software was utilized to predict potential target genes from DEMs. All the 12 DEMs were inducted into the FunRich software. There were 1980 target genes found. Then, we further assessed the intersection of 1980 target genes and 1073 DEGs, and obtained 104 overlapping genes for subsequent analysis (Fig. 5a and b). The network results of DEMs and overlapping genes were calculated using FunRich software, and the results were visualized in Cytoscape software (Fig. 5c). Notably, hsa-miR-148a targeted 22 genes, including ADAMTS18, ADAMTS5, CAV2, CCDC85A, COL6A3, DNAJB4, EMX2, FBN1, FOXF1, GPM6A, HLF, MYBL1, NDP, PRICKLE2, S1PR1, SULF1, TSPAN18, ZNF804A, B4GALT6, COL4A1, LAMA4, TGFB2; hsa-miR-133b targeted 3 genes, including SH3GL2, SFXN2, CDCA8; hsa-miR-204 targeted 5 genes, including SLC43A1, SGIP1, PRR15L, SFXN2, EPHA5; hsa-miR-222 targeted 2 genes, including STMN1 and SBK1; hsa-miR-221 targeted 2 genes, including STMN1 and SBK1; hsa-miR-31 targeted 4 genes, including MBOAT2, PPP1R9A, CTNN D2, PRSS8; hsa-miR-205 targeted 5 genes, including DSC2, NKX2-3, HS3ST1, ACSL1, EPB41L4B; hsa-miR455 targeted 5 genes, including COL2A1, HOXC4, COLEC12, KLK12, STEAP2; hsa-miR-145 targeted 5 genes, including HOMER2, IGSF5, LDLRAD3, PGM3, TMEM178A; hsa-miR-375 targeted 2 genes, including ISL2 and KCNE3; hsa-miR-376c targeted 2 genes, including ALCAM and NKX3-1; These results indicated that in all the relationships between DEMs and DEGs, miR-205 can specifically regulate the expression of autophagy-related gene NKX2-3.

\section{Construction of a interaction network between NKX2-3 and autophagy-related risk signature}

STRING database was performed to diagram a network of interacting relationships among the 17 ARGs obtained in Fig. 1a. As shown in Fig. 6a, ATG16L1 can act as a bridge node between NKX2-3 and three of the six genes risk signature (GABARAPL2, RUBCN, RAB24). In other words, we speculated whether NKX2-3 can affect above risk signature through regulating GABARAPL2, RUBCN, and RAB24 expression. To validate this network further, Pearson correlation analysis was used to determine the correlation between NKX2-3 expression and the three genes associated with the risk signature. The results indicated that significant positive correlations were 


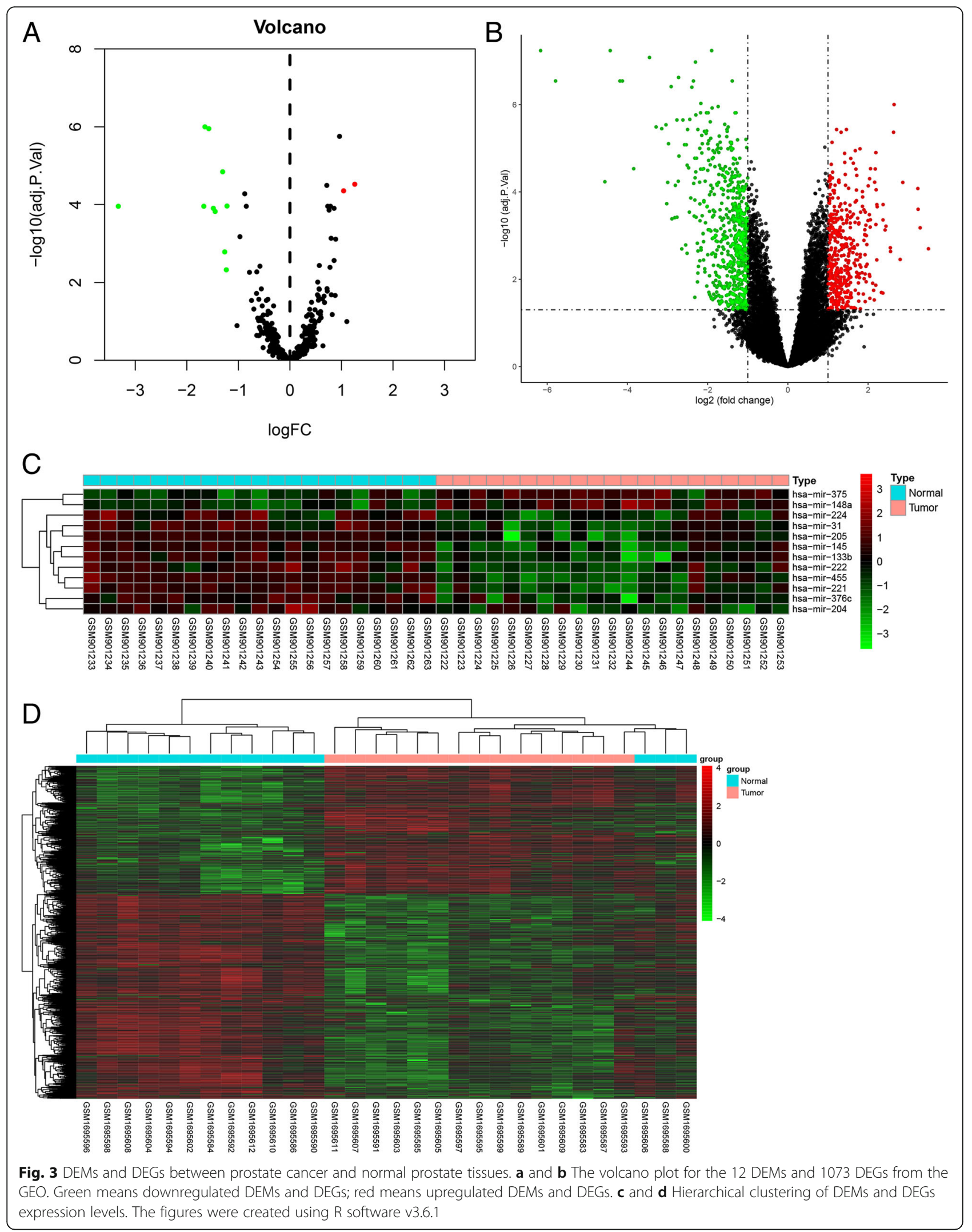




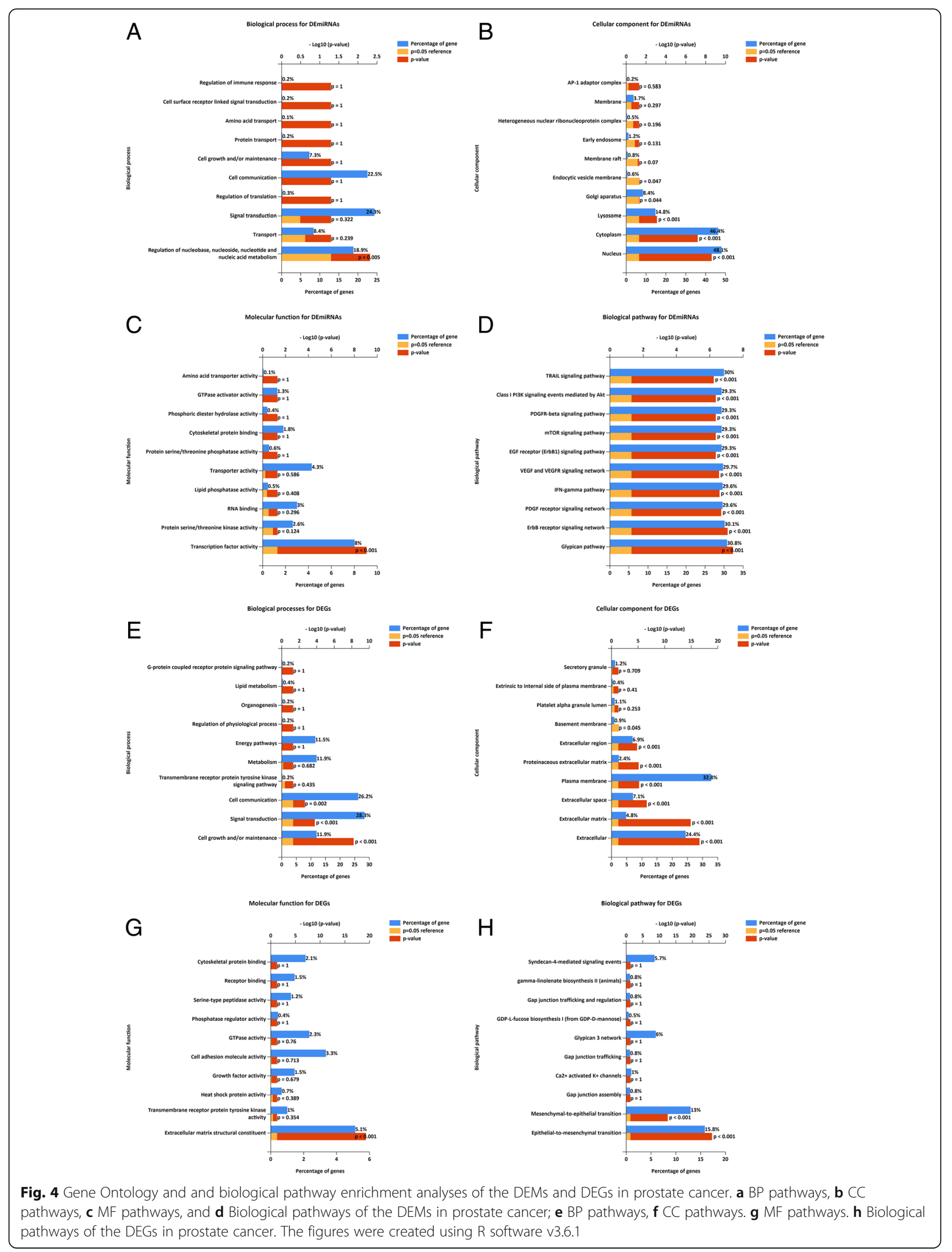




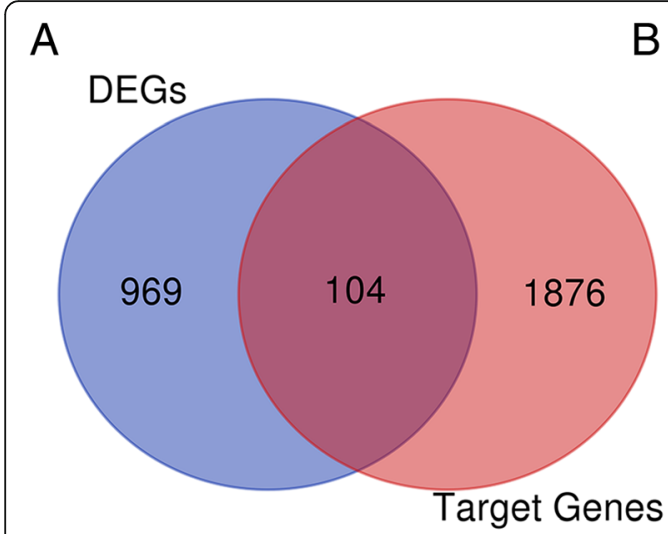

B

C
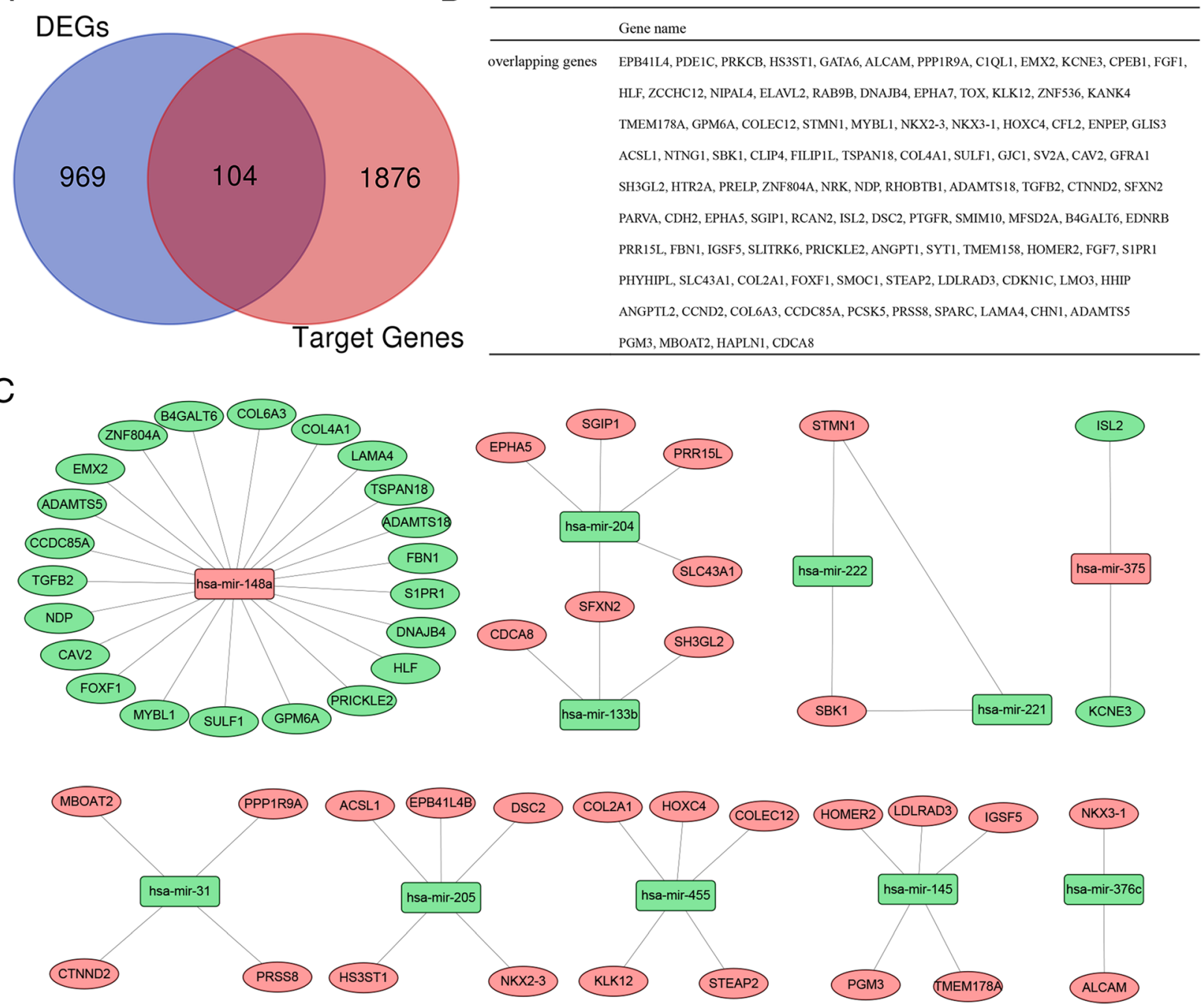

Fig. 5 A regulatory network of the overlapping genes and their target miRNAs. a Venn diagram of DEGs overlapping with DEMs target genes. $\mathbf{b}$ Names of 104 overlapping genes. c Circle nodes indicate hub genes, rectangle nodes indicate DEMs. Red nodes represent up-regulated and green nodes represent down-regulated. The figures were created using R software v3.6.1

observed between NKX2-3 and ATG16L1, GABARAPL2, KIAA0226 (RUBCN) respectively (Fig. 6b-e).

\section{Identification of differentially expressed ARGs in prostate cancer}

Altogether clinical data and transcriptome expression profiles were downloaded from TCGA. Expression values of 232 ARGs were extracted, we finally identified 5 upregulated and 8 down-regulated ARGs under cut-off criteria of FDR $<0.05$ and $|\operatorname{logFC}|>1$ (Fig. $7 \mathrm{a}$ and b). Furthermore, as presented in Fig. 7c, box plots displayed expression patterns of 8 down-regulated genes (NRG2, BCL2, NRG1, HSPB8, FAM215A, TMEM74, TP63, and ITPR1) and 5 up-regulated genes (NKX2-3, CDKN2A, BIRC5, CAMKK2, and ATG9B).

\section{Survival analysis of NKX2-3 and clinical parameters in patients with prostate cancer}

Based on the results described above, we found that the abnormally high expression of autophagy-related gene NKX2-3 in prostate cancer not only serves as a prognostic risk factor for prostate cancer patients, but also has a specific regulatory relationship with miR-205. Therefore, we further analyzed the clinical value of NKX2-3. The cBioPortal is an open-access resource for interactive exploration of multidimensional cancer genomics data sets and provides comprehensive analyses $[33,34]$. The NKX2-3 overall survival analysis using cBioPortal datasets termed prostate cancer (TCGA, Firehose Legacy). Our data showed that the altered group had a shorter overall survival time than the unaltered group (Fig. 8a). Then, we further analyzed the relationship 
A

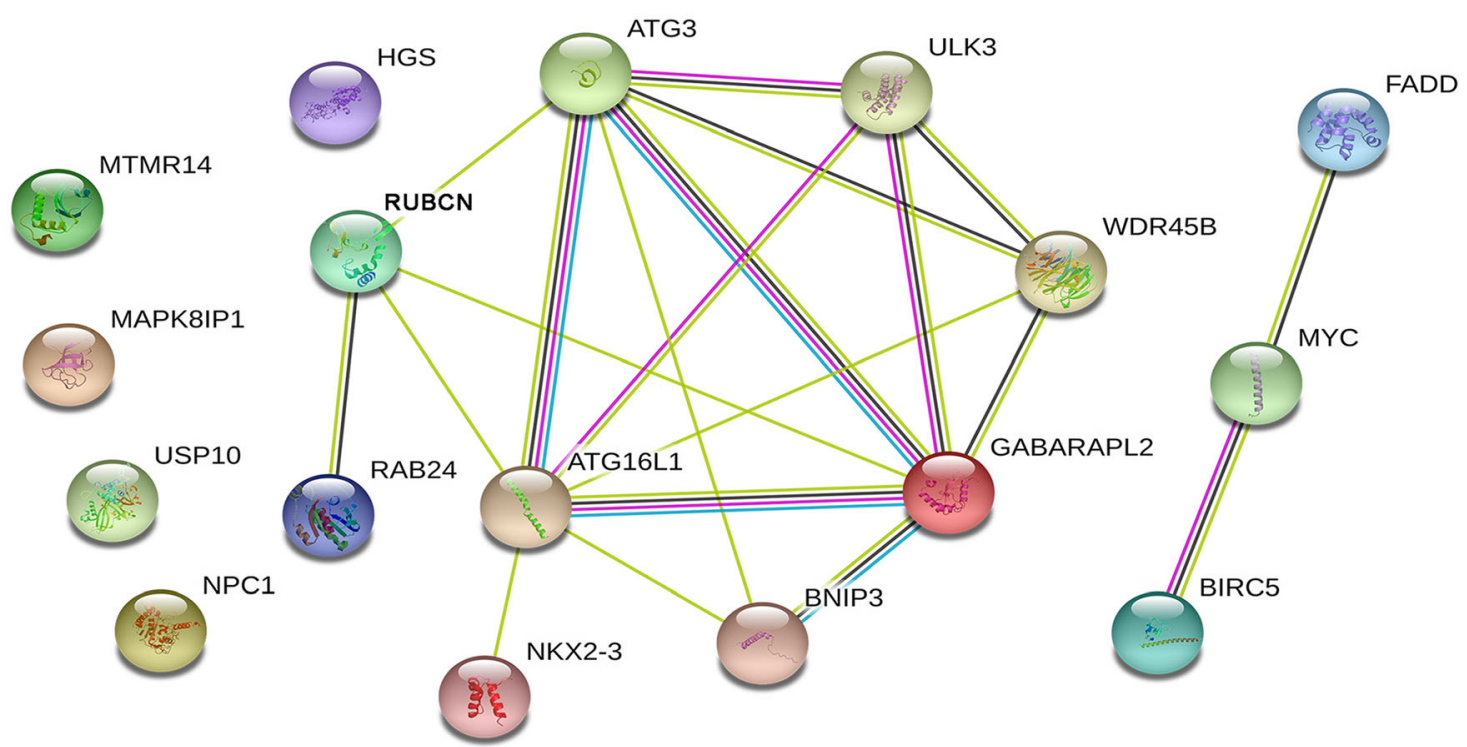

B

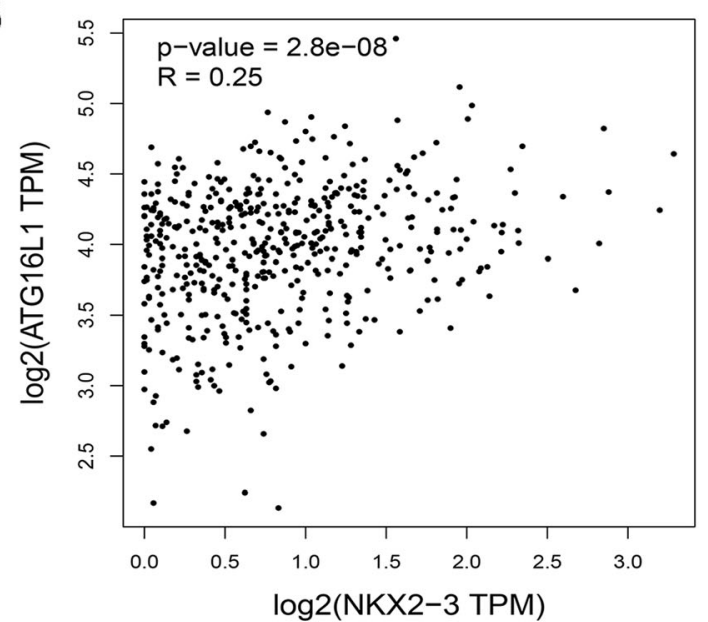

D

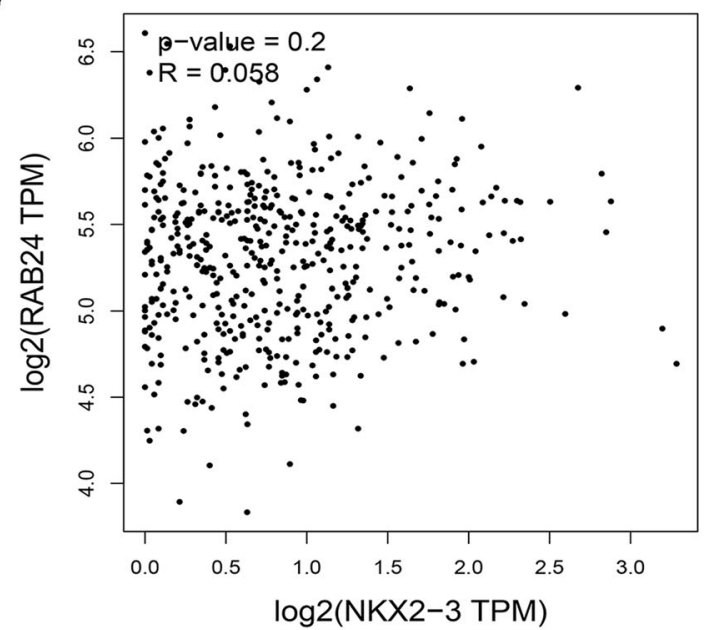

C

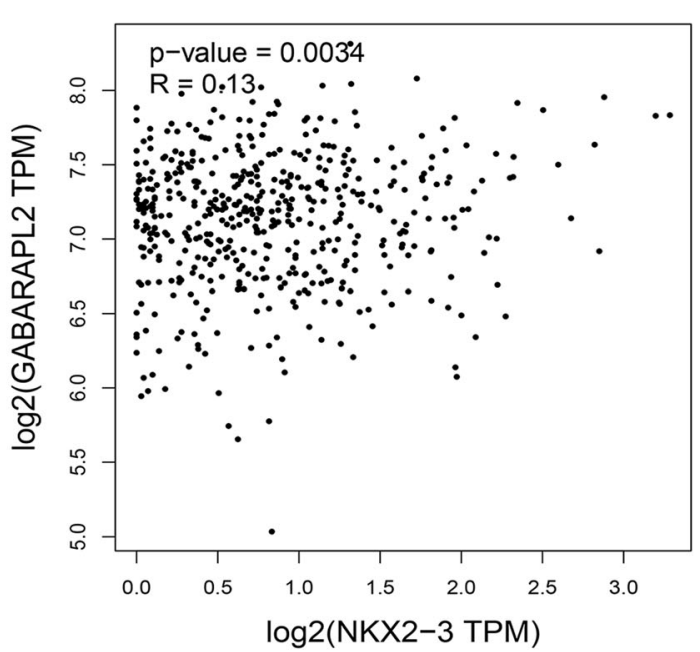

E

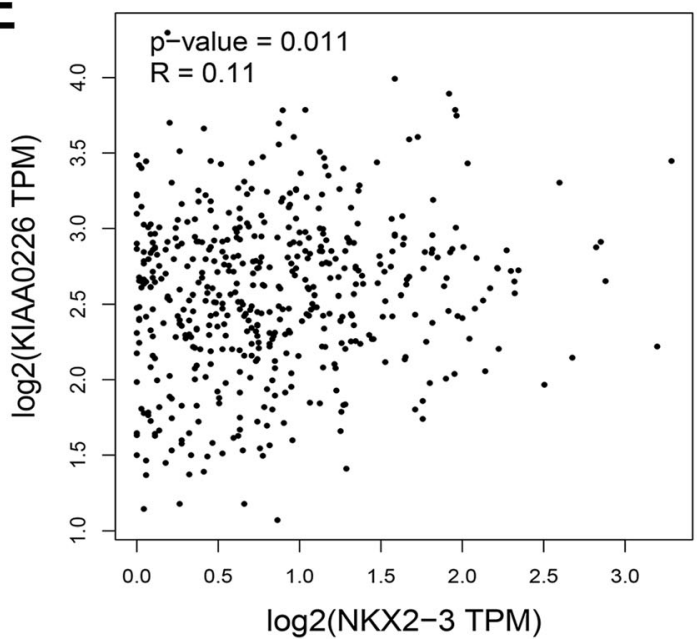

Fig. 6 Construction of a interaction network between NKX2-3 and autophagy-related risk signature. a The protein interaction network was constructed using STRING v11. Association between NKX2-3 expression and b ATG16L1, c GABARAPL2, d RAB24, e RUBCN. The figures were created using R software v3.6.1 


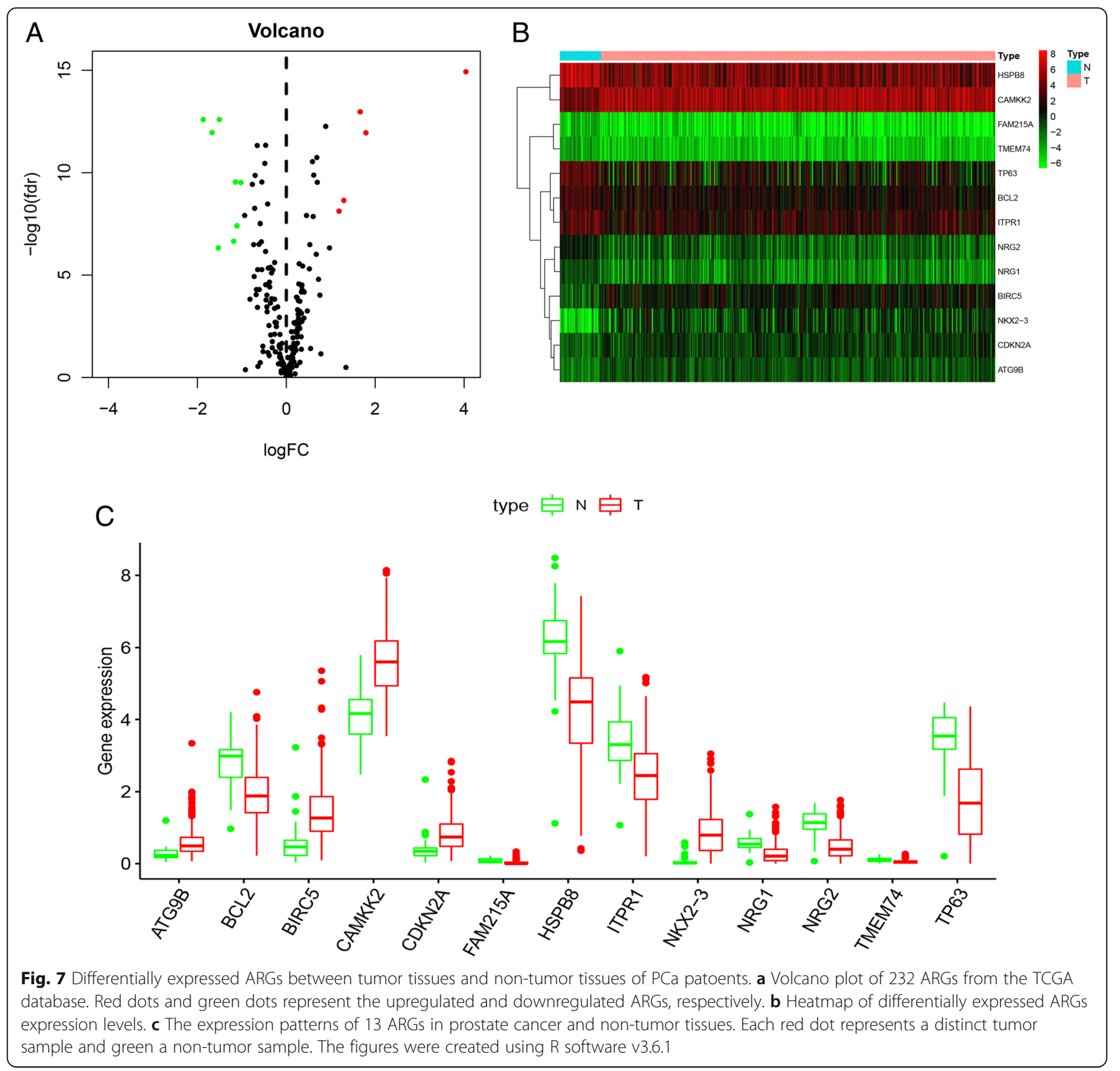

between NKX2-3 and some common clinical parameters. The results showed that the lymph nodes examined number and distant metastasis rate were significantly increased in altered group, compared with the corresponding unaltered group (Fig. 8b and c).

\section{GSEA by NKX2-3 stratification in prostate cancer}

To explore the mechanism of NKX2-3, patients were separated into high/low expression groups based on the median expression of NKX2-3 and then were subjected to GSEA. The GSEA analysis revealed that the highexpression group of NKX2-3 has strikingly upregulated genes enriched in Myc Targets V1, Unfolded Protein Response and Myc Targets V2 (Fig. 9).
NKX2-3 may serve as a potential predictor for the efficacy of anti-PD-1 therapy in prostate cancer

To further test the correlation of NKX2-3 with immunotherapy response of prostate cancer, we further analyzed the relationship between NKX2-3 and PD-1 (programmed cell death 1, PDCD1). The relevance between the expression of NKX2-3 and PD-1 was analyzed by TIMER, which is a comprehensive resource for systematical analysis of immune infiltrates across diverse cancer types $[35,36]$. Our data showed that as the expression of NKX2-3 increased, the expression of PD-1 decreased, thus NKX2-3 was negatively correlated with PD-1 in prostate cancer (Fig. 10a). Furthermore, as shown in Fig. 10b, a positive correlation was detected between 


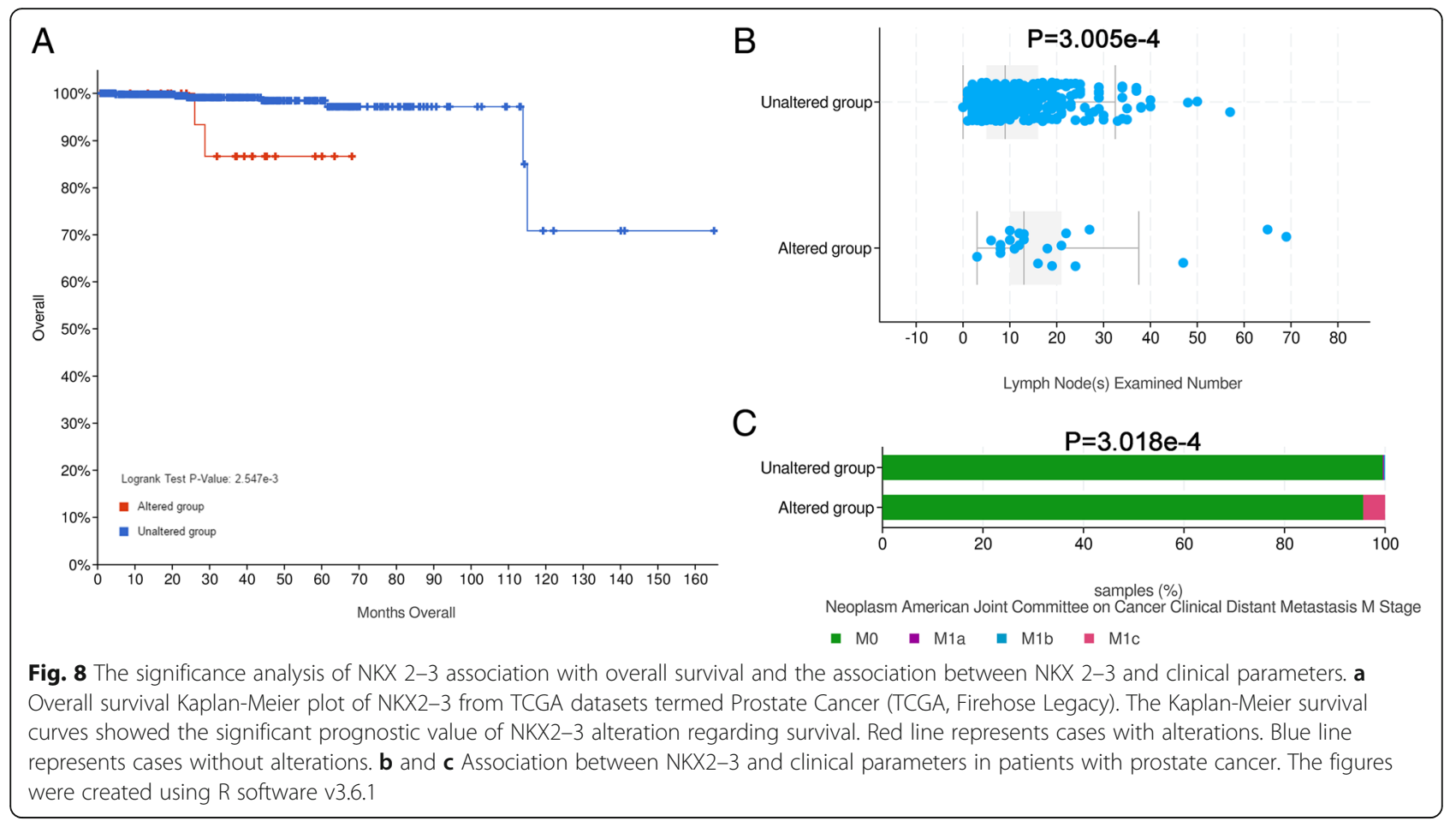

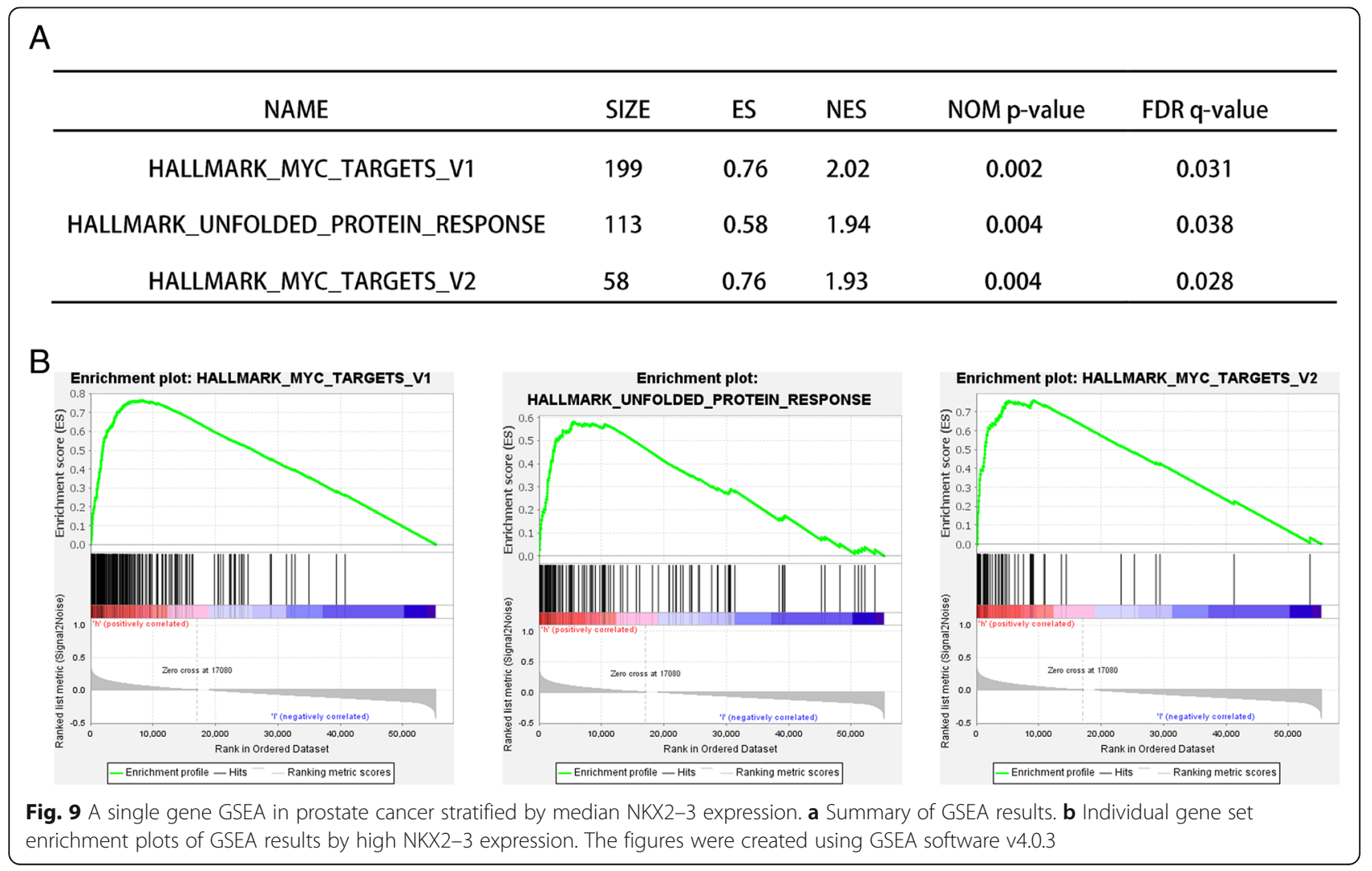



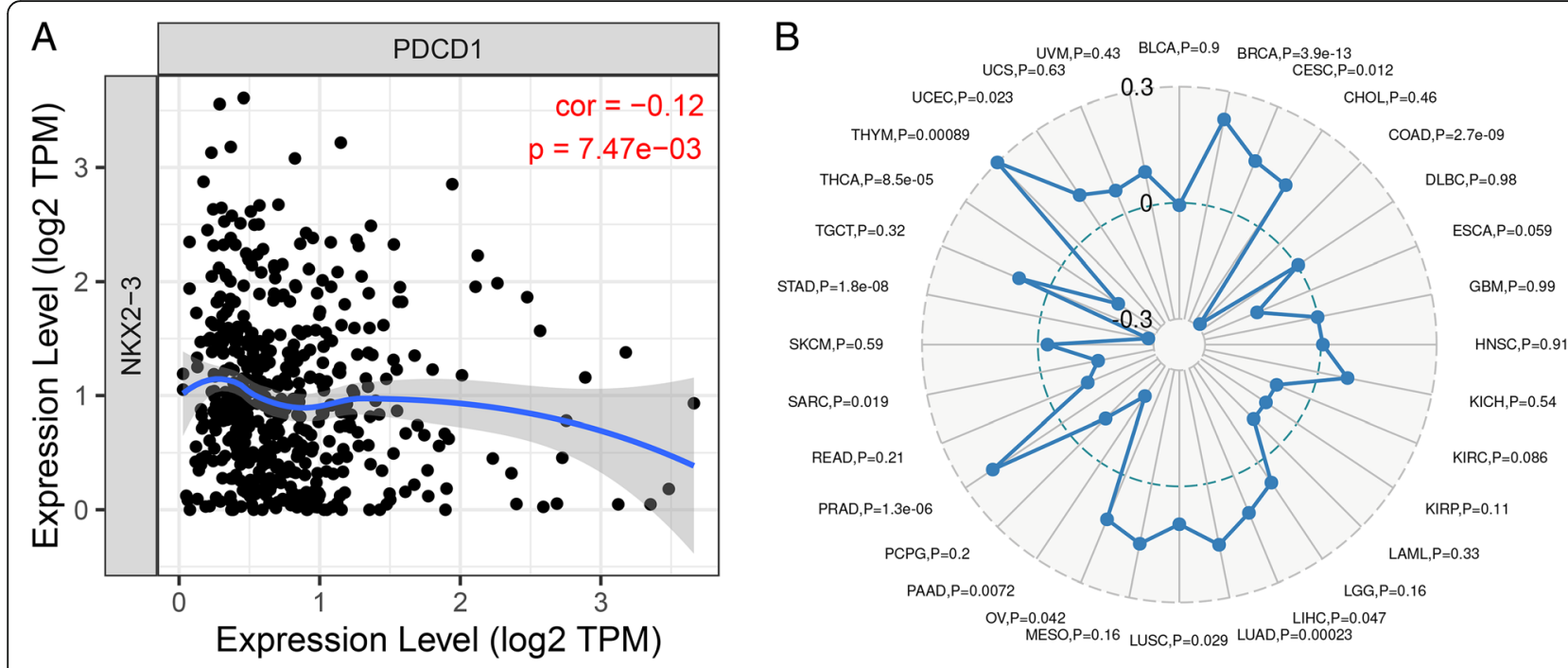

Fig. 10 Correlation analysis of NKX2-3 expression with PD-1 and TMB in prostate cancer. a Identification of the correlation between the NKX2-3 and PD-1 in prostate cancer. $\mathbf{b}$ Radar plot of NKX2-3 in relation to TMB in 32 cancer types. Green dotted line benchmarks the correlation of the NKX2-3 and TMB. The figures were created using R software v3.6.1

NKX2-3 expression and the TMB $(P<0.05$; (tumor mutation burden) of prostate cancer $(P=1.3 \mathrm{e}-06)$.

\section{Discussion}

Prostate cancer is a major lethal cancer in men worldwide. Thus, it is urgent to identify reliable prognostic biomarkers to improve the clinical treatment of prostate cancer patients. Bioinformatics prediction signatures have recently been applied to develop potential noncoding RNA and mRNA biomarkers for prostate cancer [37, 38]. Furthermore, autophagy is closely connected with tumorigenesis and therapy [39-41]. Exploration of autophagy mechanism opens new horizons for prostate cancer. However, most related studies of ARGs only focused on a signal gene. Our research used highthroughput expression profiling to capture the genes necessary for prostate cancer from the perspective of autophagy. Then, we selected more than one key prognostic ARGs, all of them may be potential therapeutic targets in prostate cancer. We further leveraged the complementary value of DEMs and ARGs and showed that miR-205 could specifically bind the autophagy-related gene NKX2-3, and NKX2-3 may be a potential predictive marker for the efficacy of anti-PD1 therapy in prostate cancer. This integrated study of multiple databases opens up a new way for the use of NKX2-3 as fresh biomarkers or molecular targets in potential diagnostic and therapeutic strategies for prostate cancer.

TCGA and GEO are the most commonly used highthroughput sequencing databases for cancer research. In our study, we first analyze the expression profiles of ARGs from TCGA and obtained a 17 autophagy-related prognostic genes (ATG16L1, FADD, GABARAPL2, NKX2-3, MYC, MAPK8IP1, WDR45B, MTMR14, HGS, USP10, NPC1, BIRC5, BNIP3, ATG3, RAB24, ULK3 and RUBCN) by univariate Cox regression analysis for detecting the prognosis of prostate cancer patients. Further multivariate Cox regression analysis was performed to select 6-gene prognostic signature (FADD, GABARAPL2, MYC, RAB24, RUBCN, and NPC1) and calculated the risk score of the prostate cancer patients. Our results suggested that the risk score is an independent prognostic factor and the predictive ability was improved by using the 6-gene risk signature when compared to using other clinical characteristics (age, $\mathrm{T}$ stage and $\mathrm{N}$ stage). Meanwhile, we deeply analyze the expression profiles from GEO database and obtained a total of 12 DEMs and 1073 DEGs (adjust $P$ value $<0.05$ and $|\log \mathrm{FC}|>1$ ) including 2 up-regulated DEMs, 10 down-regulated DEMs, 413 up-regulated DEGs and 660 down-regulated DEGs. Then, GO function (BP, CC, and MF) analysis of DEMs and DEGs demonstrated the majority of miRNAs and genes were involved in some processes and pathways, such as cell communication, and signal transduction in BP [42, 43], extracellular space, and nucleus in CC [44, 45], transcription factor activity, extracellular matrix structural constituent in MF [46, 47], which is consistent with the previous studies on tumors. Biological pathway analysis of DEGs and DEMs showed the majority of genes and miRNAs were participated in in regulating epithelial-to-mesenchymal transition [48], PI3K-Akt signaling pathway [49], mTOR pathway [50], EGF receptor pathway [51], VEGF and VEGFR network [52], IFN-gamma pathway [53], PDGF receptor network [54], and ErbB receptor signaling network [55]. Previous 
studies had shown these pathways played vital roles in PCa progression.

Recently, autophagy has emerged as a potential therapeutic target for the treatment of $\mathrm{PCa}[56,57]$. The ATG3-AKT-mTOR signaling pathway is an essential regulator of autophagy in PCa [58]. ATG3 (autophagy related 3), a known critical regulator of autophagy. It has a significant effect on mediate autophagy in PCa [59, 60]. In this study, we presented a prognostic signature to $\mathrm{PCa}$, which including six ARGs (NPC1, RUBCN, RAB24, MYC, GABARAPL2 and FADD). Of them, RAB24, RUBCN and GABARAPL2 had attracted our great interests. Because as shown in Fig. 6a, the above three ARGs were predicted closely linked with ATG3. However, the specific molecular mechanism by which ATG3 regulates RAB24, RUBCN and GABARAPL2 remains unclear and needs to be further verified in future studies.

Numerous studies have demonstrated that some of cancer-related miRs were implicated in autophagy regulation, miRs have been suggested as a potential element to mediate autophagy pathway in carcinomas [61]. Apart from the direct regulation between miRs and autophagyrelated genes, increasing evidences indicates that autophagy is capable of regulating miR homeostasis via degrading the miR-induced silencing complexes (miRISC) [62]. ARGs are crucial for cellular processes and are directly regulated by multiple miRs [63]. A number of previous studies have demonstrated that the effects of miRs on autophagy genes and proteins were critical for cancer-related outcomes. For instance, miR 23b regulates radioresistance of pancreatic cancer cells by targeting autophagy-related 12 (ATG12) [64]. MiR-205 inhibits autophagy by targeting TP53INP1 in prostate cancer cells [65]. MiR-143 inhibits cell proliferation by targeting autophagy-related 2B (ATG2B) in non-small cell lung cancer [66]. In order to verify this relation, the dual-luciferase reporter assay is the most common method. Relative luciferase activity was measured using dual luciferase assay, and the activity of firefly luciferase was normalized with that of renilla luciferase as inner control.

In our project, we predicted target genes of 12 DEMs by FunRich software, and found that among the many autophagy-related genes, NKX2-3 was predicted to have a special correlation with miR-205 in DEMs. Some studies have indicated that miR-205 is abnormally expressed in a variety of carcinomas, and miR-205 expression levels vary in humans to function as either tumor suppressors or promoters [67]. For instance, miR-205 was down-regulated in pancreatic cancer samples, and elevated miR-205 levels inhibited pancreatic cancer cell proliferation via RUNX2 [68]. In the study of ovarian cancer, miR-205 was up-regulated in tumor tissues. Upregulated miR-205 promoted the proliferation of ovarian cancer cells by targeting PTEN/SMAD4 [69]. In breast cancer research, the results revealed that the expression of miR-205-5p was decreased in breast cancer tissues and miR-205-5p may inhibit gemcitabine resistance in breast cancer cells via inhibition of ERp29 expression [70]. However, there are few studies on the function of miR-205 in autophagy and cancer, especially for miR205 and NKX2-3. The mechanism of miR-205 in cancer and autophagy still needs to be further studied.

NKX2-3 is a member of the NKX family that play critical roles in regulating lymphoid organ development, tissue differentiation, and tissue-specific gene expression [71, 72]. According to available data, NKX2-3 has been demonstrated to be down-regulated in colorectal cancer, and it may contribute to the sporadic colorectal cancer by regulating the Wnt signaling pathway $[73,74]$. In the study of gastrointestinal neuroendocrine carcinomas, people found that the expression of NKX2-3 in liver metastases was lower than that in primary tumor tissues, suggesting that NKX2-3 may be associated with the process of tumor metastasis [75]. NKX2-3 may also be classified as biomarker to predict the effects of primary advanced colorectal cancer patients who will undergo FOLFOX4 [76]. NKX2-3 has been studied not only in solid malignancies, but also in hematopoietic malignancies [77]. Therefore, it is very valuable to further study NKX2-3 in both solid malignancies and hematopoietic malignancies.

In our study, the expression of autophagy-related gene NKX2-3 was significantly up-regulated in prostate cancer tissues compared to the non-tumor tissues. According to univariate COX regression analysis results, NKX2-3 was found to be significantly correlated to OS in prostate cancer, the gene was identified as risk factor $(H R>1)$. Based on STRING analysis results, we found that the NKX2-3 was moderately related to the part of genes among the 6 autophagy-related genes prognostic signature. Then, the effect of NKX2-3 on the OS of prostate cancer was analyzed by cBioPortal database. Our data showed that patients in the altered group had a shorter overall survival time than patients in the unaltered group. Further, we analyzed the relationship between NKX2-3 and some common clinical parameters. The results showed that the lymph nodes examined number and distant metastasis rate were significantly increased in altered group, compared with the corresponding unaltered group. In order to further understand the mechanism of NKX2-3 in prostate cancer, GSEA analysis was proformed. The results showed that the high NKX2-3 expression group was correlated to biological signaling pathways, including Myc Targets V1, unfolded protein response and Myc Targets V2. As an oncogene, Myc is aberrantly expressed in the majority of types of cancer [78]. According to previous report, the 
dysregulation of Myc Targets has a good correlation with bladder cancer development [79]. Therefore, we infer that the NKX2-3 high expression group might be distinct molecular features, which is worthy of future exploration. Lastly, in terms of immunotherapy, PD-1 inhibition is a promising cancer immunotherapy [80]. Previous studies have confirmed that PD-1 inhibition could improve outcomes of cancer patients compared to chemotherapy [81, 82]. TMB was a potential biomarker and was defined as the total number of somatic mutations per megabase or the nonsynonymous mutations in tumor tissues, including replacement and insertion deletion mutations. It is reported that, the objective response rate of the PD-1 inhibition was higher in patients with high TMB than in patients with low TMB [83]. In our study, we found that the expression of NKX2-3 was significantly positively correlated with TMB in PCa. In addition, NKX2-3 expression was negatively correlated with that of PD-1 in PCa. Therefore, we speculated that the NKX2-3 may serve as a potential predictor for the efficacy of anti-PD-1 therapy in PCa.

In clinical work, anti-PD1 treatment has been shown to have superior therapy efficacy on multiple tumor types, but the response rate is still much lower than desired. Gaining a deeper understanding into biomarkers for predicting the anti-PD1therapy will possibly help us better decide which patients need anti-PD1 therapy and which patients do not in the future. In our study, we demonstrated that the NKX2-3 may be a potential biomarker for predicting the efficacy of anti-PD-1 therapy in PCa. On this basis, we can detect the expression level of NKX2-3 in PCa patients and develop individualized therapeutic strategies for anti-PD1 treatment. In the meantime, NKX2-3 and miR205 are inter-related, autophagy-related miRNAs were also found to be upregulated or downregulated in many cancers, and several studies point out to their potential use as biomarkers. Therefore, miRNA manipulations through using mimics or inhibitor, or other strategies, might potentially be used as efficacy indicators for cancer treatment.

\section{Conclusions}

In short, we identified that the six ARGs expression patterns are independent predictors of OS in PCa patients. Furthermore, our results suggest that ARGs and miRNAs are inter-related. To our knowledge at present, this is the first time that the six ARGs prognostic signature and the effect of NKX2-3 on the prediction of anti-PD1 therapy were identified in prostate cancer.

\section{Abbreviations}

PCa: Prostate cancer; ARG: Autophagy-related gene; OS: Overall survival; DEMs: Differentially expressed miRNAs; DEGs: Differentially expressed genes; TMB: Tumor mutation burden; PDCD1: Programmed cell death 1

\section{Acknowledgements}

Not applicable.

\section{Authors' contributions}

LW, YP and GZ conceived and designed the study; LW, W Q and GY analyzed the data; $Q \mathrm{~L}$ and DP revised the images. LW drafted the manuscript; YP and GZ revised the manuscript. All authors read and approved the final version of the manuscript.

\section{Funding}

The implementation of the study and writing of the manuscript were supported by the Guizhou Science and Technology Department (No. Qian Ke He LKZ [2013] 10) and Guizhou Science and Technology Department (Qian Ke He LH [2014] 7585); The analysis and interpretation of data were supported by Zunyi Medical University PhD Startup Fund. Corresponding author Zhang Guihai is the main person in charge of the above funds.

Availability of data and materials

The data in this study are available from the corresponding author on request.

\section{Ethics approval and consent to participate}

All raw data were collected from the public databases. Any repository data used in this study are open access and do not require any permissions. Ethics approval and consent to participate are not applicable for them.

Consent for publication

Not applicable.

\section{Competing interests}

The authors declare that there is no conflicts of interest to disclose.

\section{Author details}

${ }^{1}$ Department of Oncology, Zhuhai People's Hospital (Zhuhai Hospital affiliated with Jinan University), Zhuhai, Guangdong Province, P. R. China. ${ }^{2}$ Zunyi Medical University, Zunyi, Guizhou Province, P. R. China. ${ }^{3}$ Department of Oncology, Affiliated Zhuhai Hospital, Southern Medical University, Zhuhai, Guangdong Province, P. R. China.

Received: 15 July 2020 Accepted: 11 December 2020

Published online: 05 January 2021

References

1. Siegel RL, Miller KD, Jemal A. Cancer statistics, 2020. CA Cancer J Clin. 2020; 70:7-30.

2. Freytag SO, Stricker H, Movsas B, Kim JH. Prostate cancer gene therapy clinical trials. Mol Ther. 2007:15:1042-52.

3. Levy JMM, Towers CG, Thorburn A. Targeting autophagy in cancer. Nat Rev Cancer. 2017:17:528-42.

4. Li X, He S, Ma B. Autophagy and autophagy-related proteins in cancer. Mol Cancer. 2020;19:12.

5. Poillet-Perez L, White E. Role of tumor and host autophagy in cancer metabolism. Genes Dev. 2019;33:610-9

6. Farrow JM, Yang JC, Evans CP. Autophagy as a modulator and target in prostate cancer. Nat Rev Urol. 2014;11:508-16.

7. Amaravadi $\mathrm{R}$, Kimmelman AC, White $\mathrm{E}$. Recent insights into the function of autophagy in cancer. Genes Dev. 2016;30:1913-30.

8. White E, DiPaola RS. The double-edged sword of autophagy modulation in cancer. Clin Cancer Res. 2009;15:5308-16.

9. White E, Karp C, Strohecker AM, Guo Y, Mathew R. Role of autophagy in suppression of inflammation and cancer. Curr Opin Cell Biol. 2010;22:212-7.

10. Mathew R, Kongara S, Beaudoin B, Karp CM, Bray K, Degenhardt K, Chen G, Jin S, White E. Autophagy suppresses tumor progression by limiting chromosomal instability. Genes Dev. 2007;21:1367-81.

11. Lorin S, Hamaï A, Mehrpour M, Codogno P. Autophagy regulation and its role in cancer. Semin Cancer Biol. 2013;23:361-79.

12. Guo JY, White E. Autophagy, metabolism, and Cancer. Cold Spring Harb Symp Quant Biol. 2016;81:73-8.

13. Pasquinelli AE. MicroRNAs and their targets: recognition, regulation and an emerging reciprocal relationship. Nat Rev Genet. 2012;13:271-82. 
14. Xie M, Ma L, Xu T, Pan Y, Wang Q, Wei Y, Shu Y. Potential regulatory roles of MicroRNAs and long noncoding RNAs in anticancer therapies. Mol Ther Nucleic Acids. 2018;13:233-43.

15. Calin GA, Croce CM. MicroRNA signatures in human cancers. Nat Rev Cancer. 2006;6:857-66.

16. Aghdam SG, Ebrazeh M, Hemmatzadeh M, Seyfizadeh N, Shabgah AG, Azizi $\mathrm{G}$, Ebrahimi N, Babaie F, Mohammadi $\mathrm{H}$. The role of microRNAs in prostate cancer migration, invasion, and metastasis. J Cell Physiol. 2019;234:9927-42.

17. Sur S, Steele R, Shi X, Ray RB. miRNA-29b Inhibits Prostate Tumor Growth and Induces Apoptosis by Increasing Bim Expression. Cells. 2019;8:1455.

18. Xu B, Lu X, Zhao Y, Liu C, Huang X, Chen S, Zhu W, Zhang L, Chen M. MicroRNA-135a induces prostate cancer cell apoptosis via inhibition of STAT6. Oncol Lett. 2019;17:1889-95.

19. Yang B, Zhang W, Sun D, Wei X, Ding Y, Ma Y, Wang Z. Downregulation of miR-139-5p promotes prostate cancer progression through regulation of SOX5. Biomed Pharmacother. 2019;109:2128-35.

20. Aghdam AM, Amiri A, Salarinia R, Masoudifar A, Ghasemi F, Mirzaei H. MicroRNAs as diagnostic, prognostic, and therapeutic biomarkers in prostate Cancer. Crit Rev Eukaryot Gene Expr. 2019;29:127-39.

21. Moya L, Meijer J, Schubert S, Matin F, Batra J. Assessment of miR-98-5p, miR152-3p, miR-326 and miR-4289 expression as biomarker for prostate Cancer diagnosis. Int J Mol Sci. 2019;20:1154.

22. Munteanu VC, Munteanu RA, Onaciu A, Berindan-Neagoe I, Petrut B, Coman I. MiRNA-Based Inspired Approach in Diagnosis of Prostate Cancer. Medicina (Kaunas). 2020;56:94.

23. Karbasforooshan H, Roohbakhsh A, Karimi G. SIRT1 and microRNAs: the role in breast, lung and prostate cancers. Exp Cell Res. 2018;367:1-6.

24. John Clotaire DZ, Zhang B, Wei N, Gao R, Zhao F, Wang Y, Lei M, Huang W. MiR-26b inhibits autophagy by targeting ULK2 in prostate cancer cells. Biochem Biophys Res Commun. 2016;472:194-200.

25. Wang S, Guo D, Li C. Downregulation of miRNA-26b inhibits cancer proliferation of laryngeal carcinoma through autophagy by targeting ULK2 and inactivation of the PTEN/AKT pathway. Oncol Rep. 2017;38:1679-87.

26. Che J, Wang W, Huang Y, Zhang L, Zhao J, Zhang P, Yuan X. miR-20a inhibits hypoxia-induced autophagy by targeting ATG5/FIP200 in colorectal cancer. Mol Carcinog. 2019;58:1234-47.

27. Moussay E, Kaoma T, Baginska J, Muller A, Van Moer K, Nicot N, Nazarov PV, Vallar L, Chouaib S, Berchem G, Janji B. The acquisition of resistance to TNFa in breast cancer cells is associated with constitutive activation of autophagy as revealed by a transcriptome analysis using a custom microarray. Autophagy. 2011;7:760-70.

28. Pathan M, Keerthikumar S, Chisanga D, Alessandro R, Ang CS, Askenase $P$, Batagov AO, Benito-Martin A, Camussi G, Clayton A, Collino F, Di Vizio D, Falcon-Perez JM, et al. A novel community driven software for functional enrichment analysis of extracellular vesicles data. J Extracell Vesicles. 2017;6: 1321455.

29. Pathan M, Keerthikumar S, Ang CS, Gangoda L, Quek CY, Williamson NA, Mouradov D, Sieber OM, Simpson RJ, Salim A, Bacic A, Hill AF, Stroud DA, et al. FunRich: an open access standalone functional enrichment and interaction network analysis tool. Proteomics. 2015;15:2597-601.

30. Subramanian A, Tamayo P, Mootha VK, Mukherjee S, Ebert BL, Gillette MA, Paulovich A, Pomeroy SL, Golub TR, Lander ES, Mesirov JP. Gene set enrichment analysis: a knowledge-based approach for interpreting genomewide expression profiles. Proc Natl Acad Sci U S A. 2005;102:15545-50.

31. Liberzon A, Birger C, Thorvaldsdóttir H, Ghandi M, Mesirov JP, Tamayo P. The molecular signatures database (MSigDB) hallmark gene set collection. Cell Syst. 2015;1:417-25.

32. Lossos IS, Czerwinski DK, Alizadeh AA, Wechser MA, Tibshirani R, Botstein D, Levy R. Prediction of survival in diffuse large-B-cell lymphoma based on the expression of six genes. N Engl J Med. 2004;350:1828-37.

33. Cerami E, Gao J, Dogrusoz U, Gross BE, Sumer SO, Aksoy BA, Jacobsen A Byrne CJ, Heuer ML, Larsson E, Antipin Y, Reva B, Goldberg AP, et al. The cBio cancer genomics portal: an open platform for exploring multidimensional cancer genomics data. Cancer Discov. 2012;2:401-4.

34. Gao J, Aksoy BA, Dogrusoz U, Dresdner G, Gross B, Sumer SO, Sun Y, Jacobsen A, Sinha R, Larsson E, Cerami E, Sander C, Schultz N. Integrative analysis of complex cancer genomics and clinical profiles using the cBioPortal. Sci Signal. 2013;6:p11.

35. Li T, Fan J, Wang B, Traugh N, Chen Q, Liu JS, Li B, Liu XS. TIMER: a web server for comprehensive analysis of tumor-infiltrating immune cells. Cancer Res. 2017;77:e108-e10.
36. Li B, Severson E, Pignon JC, Zhao H, Li T, Novak J, Jiang P, Shen H, Aster JC, Rodig S, Signoretti S, Liu JS, Liu XS. Comprehensive analyses of tumor immunity: implications for cancer immunotherapy. Genome Biol. 2016;17:174.

37. Huang $H$, Zhang Q, Ye C, Lv JM, Liu X, Chen L, Wu H, Yin L, Cui XG, Xu DF, Liu WH. Identification of prognostic markers of high grade prostate cancer through an integrated bioinformatics approach. J Cancer Res Clin Oncol. 2017;143:2571-9.

38. Ye G, Guo L, Xing Y, Sun W, Yuan M. Identification of prognostic biomarkers of prostate cancer with long non-coding RNA-mediated competitive endogenous RNA network. Exp Ther Med. 2019;17:3035-40.

39. Li YJ, Lei YH, Yao N, Wang CR, Hu N, Ye WC, Zhang DM, Chen ZS Autophagy and multidrug resistance in cancer. Chin J Cancer. 2017;36:52.

40. Onorati AV, Dyczynski M, Ojha R, Amaravadi RK. Targeting autophagy in cancer. Nat Rev Cancer. 2018;124:3307-18.

41. Kocaturk NM, Akkoc Y, Kig C, Bayraktar O, Gozuacik D, Kutlu O. Autophagy as a molecular target for cancer treatment. Eur J Pharm Sci. 2019;134:116-37.

42. Birsu Cincin Z, Unlu M, Kiran B, Sinem Bireller E, Baran Y, Cakmakoglu B. Anti-proliferative, apoptotic and signal transduction effects of hesperidin in non-small cell lung cancer cells. Cell Oncol (Dordr). 2015;38:195-204.

43. Liu M, Xu Z, Du Z, Wu B, Jin T, Xu K, Xu L, Li E, Xu H. The identification of key genes and pathways in Glioma by bioinformatics analysis. J Immunol Res. 2017;2017:1278081.

44. He Z, Tang F, Lu Z, Huang Y, Lei H, Li Z, Zeng G. Analysis of differentially expressed genes, clinical value and biological pathways in prostate cancer. Am J Transl Res. 2018;10:1444-56.

45. Zhang $X$, Shen B, Cui Y. Ago HITS-CLIP expands microRNA-mRNA interactions in nucleus and cytoplasm of gastric cancer cells. BMC Cancer. 2019;19:29.

46. Hoesel B, Schmid JA. The complexity of NF-KB signaling in inflammation and cancer. Mol Cancer. 2013;12:86.

47. Wu K, Yi Y, Liu F, Wu W, Chen Y, Zhang W. Identification of key pathways and genes in the progression of cervical cancer using bioinformatics analysis. Oncol Lett. 2018;16:1003-9.

48. Yan Z, Xiao Y, Chen Y, Luo G. Screening and identification of epithelial-tomesenchymal transition-related circRNA and miRNA in prostate cancer. Pathol Res Pract. 2020;216:152784.

49. Xu W, Ni Z, Zhang M, Chen J, Zhang L, Wu S, Liang C. The role of polymorphisms in genes of PI3K/Akt signaling pathway on prostate. J Cancer. 2019;10:1023-31.

50. Yu Q, Li P, Weng M, Wu S, Zhang Y, Chen X, Zhang Q, Shen G, Ding X, Fu S. Nano-vesicles are a potential tool to monitor therapeutic efficacy of carbon ion radiotherapy in prostate Cancer. J Biomed Nanotechnol. 2018;14:168-78.

51. Tørring N, Dagnaes-Hansen F, Sørensen BS, Nexø E, Hynes NE. ErbB1 and prostate cancer: ErbB1 activity is essential for androgen-induced proliferation and protection from the apoptotic effects of LY294002. Prostate. 2003;56:142-9.

52. Larsson P, Syed Khaja AS, Semenas J, Wang T, Sarwar M, Dizeyi N, Simoulis A, Hedblom A, Wai SN, Ødum N, Persson JL. The functional interlink between AR and MMP9NEGF signaling axis is mediated through PIP5K1a/ pAKT in prostate cancer. Int J Cancer. 2020;146:1686-99.

53. Banzola I, Mengus C, Wyler S, Hudolin T, Manzella G, Chiarugi A, Boldorini R, Sais G, Schmidli TS, Chiffi G, Bachmann A, Sulser T, Spagnoli GC, et al. Expression of Indoleamine 2,3-Dioxygenase induced by IFN- $\gamma$ and TNF- $a$ as potential biomarker of prostate Cancer progression. Front Immunol. 2018;9:1051.

54. Nordby Y, Richardsen E, Rakaee M, Ness N, Donnem T, Patel HR, Busund LT, Bremnes RM, Andersen S. High expression of PDGFR- $\beta$ in prostate cancer stroma is independently associated with clinical and biochemical prostate cancer recurrence. Sci Rep. 2017;7:43378.

55. El Sheikh SS, Domin J, Abel P, Stamp G, Lalani el N. Androgen-independent prostate cancer: potential role of androgen and ErbB receptor signal transduction crosstalk. Neoplasia. 2003;5:99-109.

56. Mansinho A, Macedo D, Fernandes I, Costa L. Castration-resistant prostate Cancer: mechanisms, targets and treatment. Adv Exp Med Biol. 2018;1096: 117-33.

57. Sachan R, Kundu A, Jeon Y, Choi WS, Yoon K, Kim IS, Kwak JH, Kim HS. Afrocyclamin a, a triterpene saponin, induces apoptosis and autophagic cell death via the PI3K/Akt/mTOR pathway in human prostate cancer cells. Phytomedicine. 2018:51:139-50.

58. Zhang Y, Li F, Liu L, Jiang H, Jiang X, Ge X, Cao J, Wang Z, Zhang L, Wang $Y$. Salinomycin-induced autophagy blocks apoptosis via the ATG3/AKT/ mTOR signaling axis in PC-3 cells. Life Sci. 2018;207:451-60. 
59. Murrow L, Debnath J. ATG12-ATG3 connects basal autophagy and late endosome function. Autophagy. 2015;11:961-2.

60. Roy A, Ramalinga M, Kim OJ, Chijioke J, Lynch S, Byers S, Kumar D. Multiple roles of RARRES1 in prostate cancer: autophagy induction and angiogenesis inhibition. PLoS One. 2017;12:e0180344.

61. Gozuacik D, Akkoc Y, Ozturk DG, Kocak M. Autophagy-regulating microRNAs and Cancer. Front Oncol. 2017;7:65.

62. Sibony M, Abdullah M, Greenfield L, Raju D, Wu T, Rodrigues DM, GalindoMata E, Mascarenhas H, Philpott DJ, Silverberg MS, Jones NL. Microbial disruption of autophagy alters expression of the RISC component AGO2, a critical regulator of the miRNA silencing pathway. Inflamm Bowel Dis. 2015; 21:2778-86.

63. Frankel $L B$, Lund $A H$. MicroRNA regulation of autophagy. Carcinogenesis. 2012;33:2018-25.

64. Wang P, Zhang J, Zhang L, Zhu Z, Fan J, Chen L, Zhuang L, Luo J, Chen H, Liu L, Chen Z, Meng Z. MicroRNA 23b regulates autophagy associated with radioresistance of pancreatic cancer cells. Gastroenterology. 2013;145:113343.e12.

65. Wang W, Liu J, Wu Q. MiR-205 suppresses autophagy and enhances radiosensitivity of prostate cancer cells by targeting TP53INP1. Eur Rev Med Pharmacol Sci. 2016;20:92-100

66. Wei J, Ma Z, Li Y, Zhao B, Wang D, Jin Y, Jin Y. miR-143 inhibits cell proliferation by targeting autophagy-related $2 B$ in non-small cell lung cancer H1299 cells. Mol Med Rep. 2015;11:571-6.

67. Orang AV, Safaralizadeh $R$, Hosseinpour Feizi MA. Insights into the diverse roles of miR-205 in human cancers. Asian Pac J Cancer Prev. 2014;15:577-83.

68. Zhuang L, Guo J, Yao Y, Li Z. miR-205 targets runt-related transcription factor 2 to inhibit human pancreatic cancer progression. Oncol Lett. 2019; 17:843-8.

69. Chu P, Liang A, Jiang A, Zong L. miR-205 regulates the proliferation and invasion of ovarian cancer cells via suppressing PTEN/SMAD4 expression. Oncol Lett. 2018;15:7571-8.

70. Ma C, Shi X, Guo W, Feng F, Wang G. miR-205-5p downregulation decreases gemcitabine sensitivity of breast cancer cells via ERp29 upregulation. Exp Ther Med. 2019;18:3525-33.

71. Krumlauf R. Hox genes in vertebrate development. Cell. 1994;78:191-201.

72. Stanfel MN, Moses KA, Schwartz RJ, Zimmer WE. Regulation of organ development by the NKX-homeodomain factors: an NKX code. Cell Mol Biol (Noisy-le-grand). 2005;51:785-99.

73. Wang X, Zbou C, Qiu G, Fan J, Tang H, Peng Z. Screening of new tumor suppressor genes in sporadic colorectal cancer patients. Hepatogastroenterology. 2008;55:2039-44

74. Yu W, Lin Z, Pastor DM, Hegarty JP, Chen X, Kelly AA, Wang Y, Poritz LS, Koltun WA. Genes regulated by NKX2-3 in sporadic and inflammatory bowel disease-associated colorectal cancer cell lines. Dig Dis Sci. 2010;55:3171-80.

75. Leja J, Essaghir A, Essand M, Wester K, Oberg K, Tötterman TH, Lloyd R, Vasmatzis G, Demoulin JB, Giandomenico V. Novel markers for enterochromaffin cells and gastrointestinal neuroendocrine carcinomas. Mod Pathol. 2009:22:261-72.

76. Li S, Lu X, Chi P, Pan J. Identification of NKX2-3 and TGFB1I1 expression levels as potential biomarkers to predict the effects of FOLFOX4 chemotherapy. Cancer Biol Ther. 2012;13:443-9.

77. Vojkovics D, Kellermayer Z, Kajtár B, Roncador G, Vincze Á, Balogh P. NKX23-A Slippery Slope From Development Through Inflammation Toward Hematopoietic Malignancies. Biomark Insights. 2018;13:1177271918757480.

78. Stine ZE, Walton ZE, Altman BJ, Hsieh AL, Dang CV. MYC, metabolism, and Cancer. Cancer Discov. 2015:5:1024-39.

79. Jeong KC, Kim KT, Seo HH, Shin SP, Ahn KO, Ji MJ, Park WS, Kim IH, Lee SJ, Seo HK. Intravesical instillation of c-MYC inhibitor KSI-3716 suppresses orthotopic bladder tumor growth. J Urol. 2014;191:510-8.

80. Ribas A, Wolchok JD. Cancer immunotherapy using checkpoint blockade. Science. 2018;359:1350-5.

81. Borghaei H, Paz-Ares L, Horn L, Spigel DR, Steins M, Ready NE, Chow LQ, Vokes EE, Felip E, Holgado E, Barlesi F, Kohlhaufl M, Arrieta O, et al. Nivolumab versus Docetaxel in advanced nonsquamous non-small-cell lung Cancer. N Engl J Med. 2015;373:1627-39.

82. Herbst RS, Baas P, Kim DW, Felip E, Perez-Gracia JL, Han JY, Molina J, Kim JH, Arvis CD, Ahn MJ, Majem M, Fidler MJ, de Castro G Jr, et al. Pembrolizumab versus docetaxel for previously treated, PD-L1-positive, advanced non-smallcell lung cancer (KEYNOTE-010): a randomised controlled trial. Lancet. 2016; 387:1540-50.
83. Zhu J, Zhang T, Li J, Lin J, Liang W, Huang W, Wan N, Jiang J. Association between tumor mutation burden (TMB) and outcomes of Cancer patients treated with PD-1/PD-L1 inhibitions: a meta-analysis. Front Pharmacol. 2019; $10: 673$

\section{Publisher's Note}

Springer Nature remains neutral with regard to jurisdictional claims in published maps and institutional affiliations.
Ready to submit your research? Choose BMC and benefit from:

- fast, convenient online submission

- thorough peer review by experienced researchers in your field

- rapid publication on acceptance

- support for research data, including large and complex data types

- gold Open Access which fosters wider collaboration and increased citations

- maximum visibility for your research: over $100 \mathrm{M}$ website views per year

At BMC, research is always in progress.

Learn more biomedcentral.com/submissions 